\title{
Determinants of maternal adaptation to mentally disabled children in El Minia, Egypt
}

\author{
H.I. Awadalla, ${ }^{1}$ E.G. Kamel, ${ }^{2}$ E.M. Mahfouz, ${ }^{2}$ A.A. Mohamed ${ }^{3}$ and A.M. El-Sherbeeny ${ }^{4}$
}

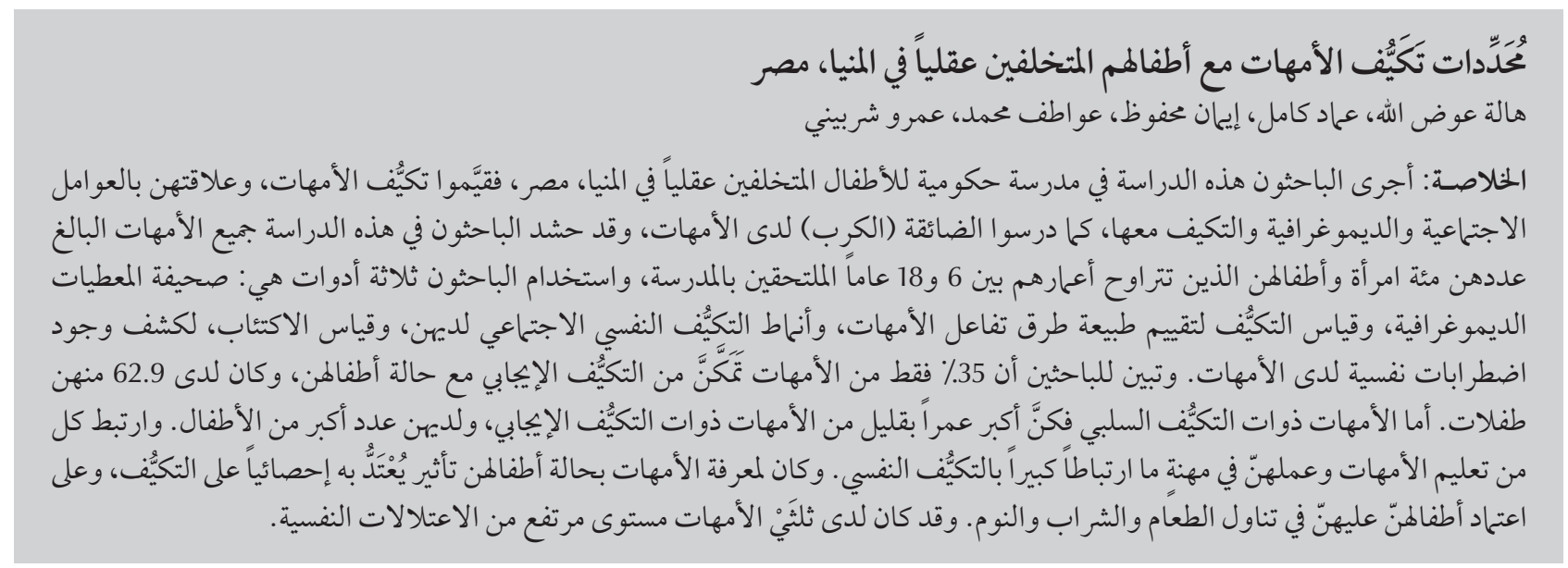

ABSTRACT This study was carried out in a governmental school for mentally disabled children in El Minia. We assessed maternal adaptation and the relationship between maternal sociodemographic factors and adaptation as well as examining maternal distress. All 100 mothers with children aged 6-18 years attending the school were recruited in the study. Three tools were used: demographic data sheet, adaptation scale to assess the nature of mothers' interaction and patterns of psychosocial adaptation and depression scale to detect the presence of psychiatric disorders among the mothers. Only $35.0 \%$ of the mothers adapted positively to their child's condition; $62.9 \%$ of those had female children. Negatively adapted mothers were slightly older than positively adapted mothers and had more children. Maternal education and occupation were significantly associated with psychosocial adaptation. Knowledge of mothers about their child's condition significantly affected adaptation as well as the dependency of children in eating, drinking and sleeping. Two-thirds of mothers had high levels of psychopathology.

\section{Déterminants de l'adaptation maternelle aux enfants souffrant d'incapacité mentale à El Minia (Égypte)}

RÉSUMÉ Cette étude a été effectuée dans une école publique pour enfants souffrant d'incapacité mentale à EI Minia. Nous avons évalué l'adaptation de la mère et la relation existant entre les facteurs sociodémographiques de la mère et son adaptation; nous avons également analysé la détresse maternelle. La totalité des 100 mères ayant des enfants âgés de 6 à 18 ans scolarisés dans cette école a participé à l'étude. Trois outils ont été utilisés : une fiche technique démographique; une échelle d'adaptation permettant d'évaluer la nature de l'interaction des mères et les modèles d'adaptation psychosociale ; et une échelle de dépression afin de détecter la présence de troubles psychiatriques chez les mères. Seules 35,0 \% des mères se sont adaptées de manière positive à l'état de leur enfant; parmi elles, 62,9\% avaient des enfants de sexe féminin. Les mères présentant une adaptation négative étaient légèrement plus âgées que celles s'étant adaptées positivement, et avaient davantage d'enfants. L'instruction et la profession de la mère étaient associées de manière significative à l'adaptation psychosociale. Les connaissances des mères au sujet de l'état de leur enfant influaient considérablement sur leur adaptation ainsi que sur la dépendance de l'enfant pour manger, boire et dormir. Les deux tiers des femmes présentaient des niveaux élevés de psychopathologie.

'Institute of Environmental Studies and Research, Ain Shams University, Cairo, Egypt (Correspondence to H.I. Awadalla: hala_awadalla@yahoo.com). ${ }^{2}$ Department of Public Health; ${ }^{4}$ Department of Neurology, Faculty of Medicine; ${ }^{3}$ Department of Community Health, Faculty of Nursing, El-Minia University, El Minia, Egypt.

Received: 02/07/08; accepted: 21/09/08 


\section{Introduction}

Mothers, who are the primary providers of care for children with mental disabilities, face many challenges and stressors that may lead to maternal distress if not well adjusted and adapted. For most children with disabilities, their disability is not a fixed condition, but is changeable over time and with circumstances and offered care. A single disability could be complicated by multiple disabilities if care, love and support are lacking [1].

Mothers of children with mental disability may not only face greater challenges owing to their child's condition, they may also be less equipped to deal with those challenges. The strongest and most consistent predictor of maternal outcomes is the extent and severity of the behavioural symptoms of the child [2]. Children with mental disability and their mothers are at increased risks for psychosocial problems compared to their peers [3].

When a mother or primary caregiver experiences depression or other stressrelated mood problems and does not manage her stress appropriately when she is with her child, the child is more likely to be directly affected [4].

In Egypt, medical and rehabilitation care services are available and are provided by governmental and nongovernmental organizations. However, they do not cover actual needs, particularly in rural areas and peri-urban areas. Teachers in some institutions for children with intellectual impairments were trained as part of a project to upgrade public special education institutions [5]

Adaptation theory acknowledges that human beings struggle continuously to survive, adapt and change their environment as well as to deal with challenges that can be present in these environments [6]. Mother and child adaptation is mutually interrelated. Children tend to adapt most successfully to living with a chronic illness when their mothers and family functioning remain strong [3,7]. Maternal anxiety is the main factor causing poor adaptation in a child with mental retardation which makes the child liable to negative outcomes [8].

Other challenges that can be stressful to mothers included time spent in managing illness and in daily care giving activities, financial difficulties caused by unexpected expenses and increased use of health services to treat and help manage the condition, decreased family socialization activities which alter family life dramatically $[9,10]$.

Identification of the stressors that lead to maladjustment of mothers with mentally-disabled children and cause maternal distress will help pave the way towards its elimination or appropriate intervention by special support groups and programmes to help mothers to care for their children.

We focused on mothers because they still tend to have primary responsibility for child care and are most subject to the challenges associated with their child's disability. We aimed to assess maternal adaptation towards their child with mental disabilities, describing the relationship between maternal sociodemographic factors and their adaptation and determining the presence of maternal distress.

Research hypothesis: mothers with mentally disabled children are not adapted to their life and usually suffer from depression.

\section{Methods}

El Minia city is the capital of El Minia governorate in Upper Egypt ,located about $240 \mathrm{~km}$ south of Cairo. The city has only 1 governmental school for mentally disabled children, El-Fekrya School. All mothers with children aged 6-18 years old attending the school were invited to participate in the study. The total was 111; 11 mothers refused to participate, so the total number included in the study was 100 . This study was carried out during the period February-May 2008.

Three tools were used for data collection:

Demographic data sheet: a structured questionnaire was designed by the researchers to collect information about mothers' age, education level, occupation, number of children, social status and residence. It also included questions about child's age, sex, rank in the family, degree of child independence in daily activities as well as mothers' knowledge about the illness.

Adaptation scale: this was developed and applied for the Egyptian culture by Hewalla [11]. It was used to assess the nature of mothers' interaction and patterns of psycho-social adaptation toward their mentally ill children. Items were marked positive or negative; the following scores were used for positive items: 4 points for agree, 3 points for not sure and 2 points for disagree. For negative items: 2 points for agree, 3 points for not sure and 4 points for disagree. Total score $\geq 65$ indicated a positive attitude, while score $<65$ indicated a negative attitude toward adaptation [12].

Depression scale: The Structured Clinical Interview for DSM-III-R was used to detect the presence of psychiatric disorders in mothers of mentally disabled children in the past year [13]. Mothers were screened for the presence of depressive disorders, panic disorder, social phobia, specific phobia, obsessive-compulsive disorder and generalized anxiety disorder. They were also screened to detect subsyndromal presentations of these disorders.

A pilot study was conducted on $10 \%$ of the studied participants (since there is only 1 school for the mentally disabled in El Minia). Necessary modifications to the questionnaire were carried out on the basis of the pilot study. Informed, written consent was taken from every mother participating in the study. Each mother was individually interviewed. 
The data were examined for significant associations using SPSS, version 13. Quantitative data were presented as mean and standard deviation (SD) while qualitative data were presented as frequencies and percentages. The chi-squared and Student $t$-tests were used for comparison of categorical variables and continuous variables respectively. $P<0.05$ was considered to indicate a statistically significant difference.

Multiple linear regression was used to predict the presence or absence of maternal adaptation based on a set of predictor variables. The logistic regression coefficients were used to estimate $t$-value for each of the independent variables in the model. $P<0.05$ was considered to indicate a statistically significant difference.

\section{Results}

All 100 mothers were assessed for psychosocial adaptation toward their children's disability. The mean age was 39.2 (SD 5.3) years (Table 1).

Almost two-thirds of mothers adapted negatively to their children's disability (Table 2). There was a significant relationship between maternal adaptation and sex of the child: just over three-quarters of mothers of male children were negatively adapted. With regard to birth order, $60 \%$ of single and $71.9 \%$ of the second or higher birth orders had negatively adapted mothers, however if the disabled child was the first born, just over half the mothers were negatively adapted; the relation between birth order and maternal adaptation was not statistically significant.
Maternal education and occupation were significantly associated with psychosocial adaptation (Table 1). More than three-quarters of illiterate mothers were negatively adapted $(P<0.05)$. The majority of housewives $(72.6 \%)$ were also negatively adapted $(P<0.05)$.

Knowledge of the mothers about their children's condition was significantly associated with maternal adaptation. Few mothers reported that they had complete information or read about their child's condition (Table 3). In general, mothers who reported that they did not know anything about the definition, etiology, manifestation, management and complications of the illness were for the most part negatively adapted.

The relationships between maternal adaptation and the child's dependency in selected activities of daily living are

\begin{tabular}{|c|c|c|c|c|}
\hline \multirow[t]{2}{*}{ Sociodemographic characteristic } & \multicolumn{2}{|c|}{ Negative adaptation } & \multicolumn{2}{|c|}{ Positive adaptation } \\
\hline & No. & $\%$ & No. & $\%$ \\
\hline \multicolumn{5}{|l|}{ Mother's education } \\
\hline Illiterate $(n=70)$ & 55 & 78.6 & 15 & 21.4 \\
\hline \multirow[t]{2}{*}{ Educated $(n=30)$} & 10 & 33.3 & 20 & 66.7 \\
\hline & \multicolumn{4}{|c|}{$\chi^{2}=16.9 ; P=0.001$} \\
\hline \multicolumn{5}{|l|}{ Mother's occupation: } \\
\hline Housewife $(n=73)$ & 53 & 72.6 & 20 & 27.4 \\
\hline \multirow[t]{2}{*}{ Employed $(n=27)$} & 12 & 44.4 & 15 & 55.6 \\
\hline & \multicolumn{4}{|c|}{$\chi^{2}=5.69 ; P=0.02$} \\
\hline \multicolumn{5}{|l|}{ Marital status } \\
\hline Married $(n=91)$ & 60 & 65.9 & 31 & 34.1 \\
\hline Divorced $(n=5)$ & 3 & 60.0 & 2 & 40.0 \\
\hline \multirow[t]{2}{*}{ Widowed $(n=4)$} & 2 & 50.0 & 2 & 50.0 \\
\hline & \multicolumn{4}{|c|}{$\chi^{2}=0.49 ; P=0.78$} \\
\hline \multicolumn{5}{|l|}{ Residence } \\
\hline Urban $(n=60)$ & 40 & 66.7 & 20 & 33.3 \\
\hline \multirow[t]{2}{*}{ Rural $(n=40)$} & 25 & 62.5 & 15 & 37.5 \\
\hline & \multicolumn{4}{|c|}{$\chi^{2}=0.18 ; P=0.67$} \\
\hline \multirow[t]{2}{*}{ Total $(n=100)$} & 65 & 65.0 & 35 & 35.0 \\
\hline & Mean & SD & Mean & SD \\
\hline \multirow[t]{2}{*}{ Age of mother(years) } & 39.4 & 4.4 & 38.9 & 4.2 \\
\hline & \multicolumn{4}{|c|}{$t=0.11 ; P=0.89$} \\
\hline \multirow[t]{2}{*}{ Number of children in the family } & 3.2 & 1.9 & 2.7 & 1.3 \\
\hline & \multicolumn{4}{|c|}{$t=1.55 ; P=0.14$} \\
\hline
\end{tabular}

$S D=$ standard deviation. 


\begin{tabular}{|c|c|c|c|c|}
\hline \multirow{2}{*}{$\begin{array}{l}\text { Child's } \\
\text { characteristic }\end{array}$} & \multicolumn{2}{|c|}{ Negative adaptation } & \multicolumn{2}{|c|}{ Positive adaptation } \\
\hline & No. & $\%$ & No. & $\%$ \\
\hline \multicolumn{5}{|l|}{ Sex } \\
\hline Male $(n=55)$ & 42 & 76.4 & 13 & 23.6 \\
\hline \multirow[t]{2}{*}{ Female $(n=45)$} & 23 & 51.1 & 22 & 48.9 \\
\hline & \multicolumn{4}{|c|}{$\chi^{2}=6.9 P=0.001$} \\
\hline \multicolumn{5}{|l|}{ Age (years) } \\
\hline $6-12(n=33)$ & 18 & 45.5 & 15 & 45.5 \\
\hline \multirow[t]{2}{*}{$>12-18(n=67)$} & 47 & 70.1 & 20 & 29.9 \\
\hline & \multicolumn{4}{|c|}{$\chi^{2}=1.73 P=0.18$} \\
\hline \multicolumn{5}{|l|}{ Birth order } \\
\hline Single $(n=5)$ & 3 & 60.0 & 2 & 40.0 \\
\hline First $(n=31)$ & 16 & 51.6 & 15 & 48.4 \\
\hline \multirow[t]{2}{*}{ Second $+(n=64)$} & 46 & 71.9 & 18 & 28.1 \\
\hline & \multicolumn{4}{|c|}{$\chi^{2}=3.83 P=0.15$} \\
\hline Total $(n=100)$ & 65 & 65.0 & 35 & 35.0 \\
\hline
\end{tabular}

\begin{tabular}{|c|c|c|c|c|}
\hline \multirow{2}{*}{$\begin{array}{l}\text { Category/ } \\
\text { knowledge level }\end{array}$} & \multicolumn{2}{|c|}{ Negative adaptation $(n=65)$} & \multicolumn{2}{|c|}{ Positive adaptation $(n=35)$} \\
\hline & No. & $\%$ & No. & $\%$ \\
\hline \multicolumn{5}{|l|}{ Definition } \\
\hline Complete & 3 & 4.6 & 5 & 14.3 \\
\hline Incomplete & 12 & 18.5 & 18 & 51.4 \\
\hline \multirow[t]{2}{*}{ Don't know } & 50 & 76.9 & 12 & 34.3 \\
\hline & \multicolumn{4}{|c|}{$\chi^{2}=17.6 P=0.001$} \\
\hline \multicolumn{5}{|l|}{ Etiology } \\
\hline Complete & 1 & 1.5 & 9 & 25.7 \\
\hline Incomplete & 29 & 44.6 & 11 & 31.4 \\
\hline \multirow[t]{2}{*}{ Don't know } & 35 & 53.9 & 15 & 42.9 \\
\hline & \multicolumn{4}{|c|}{$\chi^{2}=14.8 P=0.001$} \\
\hline \multicolumn{5}{|l|}{ Manifestations } \\
\hline Complete & 2 & 3.1 & 8 & 22.8 \\
\hline Incomplete & 21 & 32.3 & 15 & 42.9 \\
\hline \multirow[t]{2}{*}{ Don't know } & 42 & 64.6 & 12 & 34.3 \\
\hline & \multicolumn{4}{|c|}{$\chi^{2}=13.5 P=0.001$} \\
\hline \multicolumn{5}{|l|}{ Management } \\
\hline Complete & 1 & 1.5 & 3 & 8.6 \\
\hline Incomplete & 9 & 13.8 & 10 & 28.6 \\
\hline \multirow[t]{2}{*}{ Don't know } & 55 & 84.7 & 22 & 62.8 \\
\hline & \multicolumn{4}{|c|}{$\chi^{2}=6.8 P=0.03$} \\
\hline \multicolumn{5}{|l|}{ Complications } \\
\hline Complete & 2 & 3.1 & 10 & 28.6 \\
\hline Incomplete & 6 & 9.2 & 3 & 28.6 \\
\hline \multirow[t]{2}{*}{ Don't know } & 57 & 87.7 & 22 & 62.8 \\
\hline & \multicolumn{4}{|c|}{$\chi^{2}=14.1 P=0.001$} \\
\hline
\end{tabular}

shown in Table 4. By regression analysis, only dependency in eating, drinking and sleeping were strong predictors of maternal adaptation

Mothers of mentally disabled children had high levels of psychopathology: 66\% had either a syndromal disorder (27\%), a subsyndromal disorder (28\%), or both (11\%). Generalized anxiety (32\%) and dysthymic disorder (24\%) were the most common disorders followed by major depressive disorder and depression subsyndrome (both 18\%) (Table 5).

\section{Discussion}

Almost two thirds of mothers with mentally disabled children in this study were negatively adapted to the condition of their children. These findings are in accordance with Johanson who reported that mothers were usually the primary caregivers of chronically ill children [14]. They might experience greater demands upon their personal resources and consequently were more distressed and maladapted. In comparison, Gosch reported that more than half the mothers of mentally disabled children showed negative adaptation to their children and found difficulty accepting them [15].

There was a statistically significant relationship between maternal adaptation and sex of the mentally disabled children. This was similar to what was found by Azar and Solomon [16], they found that the child's sex had an effect on mother's feelings of self-confidence and adaptation in managing the case and that the mother had more confidence when the child was a girl. Similarly, Mott, James and Sperhac stated that the child's sex could increase the risk of maladaptation and psychological burden for mothers and that some mothers may perceive that the disease is more serious in boys than in girls [17].

It was clear from the results of the presentstudy that there was a statistically 


\begin{tabular}{lccccc}
\hline Table 4 Multiple linear regression analysis of child's dependency & related to maternal adaptation & & \\
Dependency item & Unstandardized y & Standardized & $\boldsymbol{t}$ & \\
& B & SE & Beta & & \\
Constant & 0.959 & 0.199 & & 4.820 & 0.001 \\
Eating & -0.529 & 0.091 & -0.881 & 5.800 & 0.001 \\
Drinking & 0.400 & 0.114 & 0.625 & 3.490 & 0.001 \\
Sleeping & 0.224 & 0.060 & 0.325 & 3.761 & 0.001 \\
Defecation & 0.187 & 0.132 & 0.303 & 1.410 & 0.161 \\
Self cleaning after toilet & 0.213 & 0.012 & 0.025 & 0.841 & 0.651 \\
Bathing & 0.007 & 0.079 & 0.114 & 1.010 & 0.317 \\
Clothes care & 0.005 & 0.093 & 0.086 & 0.584 & 0.560 \\
Urination & 0.005 & 0.123 & 0.085 & 0.457 & 0.649 \\
Treatment & 0.003 & 0.063 & 0.053 & 0.525 & 0.601 \\
Going to school & 0.003 & 0.079 & 0.044 & -0.455 & 0.650 \\
\hline SE
\end{tabular}

$S E=$ standard error

significant difference between maternal adaptation and their employment status and education: positive adaptation was more common among working mothers and those who were educated. Educated mothers can be more helpful in the adaptation process, Jeprrett showed that the highly educated parents learned to manage their child's illness and move from the early struggle with adaptation to more competent care [18]. Working mothers had more experience due to their presence in the community and greater experience, which helped them deal with the problem. These findings agreed with Fuller and Schaller [19] and Refatt [20] who reported a significant relationship between maternal adaptation and occupation. Working and/or educated mothers know that they are not alone having such a problem, and this may be helpful in the adaptation process. These findings were also supported by Zin El-Dean [9], who noted that educated and working mothers had higher levels of adaptation than illiterate and non-working mothers.

There were significant effects of maternal knowledge about the child's condition on their adaptation. A study by Doornbos supported this point; he found that caregivers of mentally retarded children identified the beneficial effect of increasing their knowledge in

\begin{tabular}{lcc}
\hline $\begin{array}{l}\text { Table } 5 \text { Frequency distribution of psychiatric disorders in mothers of children } \\
\text { with mental disability }(\boldsymbol{n}=\mathbf{1 0 0})\end{array}$ & No. & $\%$ \\
\hline Psychiatric disorder & 32 & 32 \\
Generalized anxiety & 24 & 24 \\
Dysthymia & 18 & 18 \\
Depression subsyndrome & 18 & 18 \\
Major depression & 14 & 14 \\
Generalized anxiety disorder & 12 & 12 \\
Panic disorder & 8 & 8 \\
Social phobia subsyndrome & 2 & 2 \\
Obsessive-compulsive subsyndrome & 2 & 2 \\
Social phobia & 2 & 2 \\
Specific phobia & 0 & 0 \\
Obsessive-compulsive disorder & \\
\hline
\end{tabular}

More than one diagnosis was possible for each individual.

the adaptation process and that $88 \%$ of mothers felt better about themselves by learning to manage their child's condition [21].

Melnykreported that the commonly cited source of stress and maladaptation for mothers was the difficult day-to-day health care, which was time consuming and described as the chronic burden of care [22]. He added that mothers of the mentally ill children often experienced more strain related to time spent caring for the disabled child as well as higher levels of psychological distress than mothers of healthy children. We found a statistically significant relationship between maternal adaptation and children dependency in activities such as eating, drinking and sleeping. Abd El-Megeed [23] found a statistically significant difference between adaptation of mothers having children with mental disabilities and dependency of these children on their mothers in regard to defecation, urination and clothes care.

In this study, we found that depressive disorders were common among the reported psychiatric disorders. These results are in agreement with the findings of Singer [24] who reported that there was an increased psychiatric morbidity, particularly depressive disorders, in the mothers of mentally disabled children. 
To sum up, the mothers of children with mental disabilities adapted negatively to their children's condition. Factors affecting the adaptation of the mothers were maternal sociodemographic characteristics, sex of the child, the mothers' knowledge about the condition and dependency of the child in some activities of daily living. They had high levels of psychopathology, including a syndromal diagnosis, a subsyndromal disorder, or both.

Given that the majority of the mothers displayed a high burden and poor adaption to their situation, there is a real need for better and more specific support and interventions for mothers caring for mentally disabled children in order to help avoid the development of maternal psychiatric disorders.

\section{References}

1. Shaw $\mathrm{P}$ et al. Barriers to inclusive child care: executive summary of research study findings and recommendations. Sacramento, California, Children and Families Commission, 2001.

2. Witt WP, Rily AW, Jo Coiro M. Childhood functional status, family stressors, and psychosocial adjustment among schoolaged children with disabilities in the United States. Archives of Pediatrica and Adolescent Medicine, 2003, 157:68-95.

3. Wallander J, Varni J. Effects of pediatric chronic physical disorders on child and family adjustment. Journal of Children Psychology and Psychiatry, 1998, 1:29-46.

4. Reyes RL. Infant mental health:from parenting to policymaking in children's mental health. Madison, Wisconsin, Wisconsin Council on Children and Families, Inc., 2002 (http://www.wccf. org/pdf/wiskids_mentalhealth.pdf, accessed 2 May 2010).

5. Implementation of the United Nations standard rules on the equalization of opportunities for persons with disabilities, report on the inter-country meeting for the Eastern Mediterranean Region, Cairo (Egypt), 2-4 May, 2006. Cairo, World Health Organization Regional Office for the Eastern Mediterranean, 2007:27-40.

6. Mohr K, Lafuze E, Brain D. Opening caregiver minds: National Alliance for Mentally III's provider education program. Archives of Psychiatric Nursing, 2000, 5:238-251.

7. Allen P, Vessy J. Primary care of the child with chronic condition, 4th ed. St Louis, Mosby, 2004:8-12.

8. El-Nimr A. Intelligence and psychosocial adjustment in children with chronic diseases [Masters thesis]. Cairo, Faculty of Medicine, Cairo University, 2001.

9. Zin El-Dean M. Children adaptation to chronic illness and related factors [Doctorate dissertation]. Menofya, Egypt, El-Menofya University Faculty of Nursing, 2000.

10. Yantzi $\mathrm{N}$ et al. The impacts of distance to hospital on families with children with chronic condition. Social Science \& Medicine, 2001, 52(12):1777-1791.

11. Hewalla A. Family attitudes toward slow learner [Doctorate dissertation]. Cairo, Faculty of Education, Ain Shams University, 1994.

12. Khalil AA et al. Maternal adaptation toward their children with chronic conditions. Alexandria Scientific Nursing Journal, 2006, 5(2):83-98.
13. Spitzer RL, Davies M, Barkley RA. The DSM-III-R field trial of disruptive behavior disorders. Journal of the American Academy of Child and Adolescent Psychiatry, 1990, 29(5):690-697.

14. Johanson S. Health illness and families, 2nd ed. New York, Harcourt Health Science, 2005:220-233.

15. Gosch A. Maternal stresses among mothers of children with Williwims-Beuren syndrome, Down's syndrome, and mental retardation of non-syndromal etiology in comparison to mothers of non-disabled children. Zeitschrift für Kinder und Jugendpsychiatrie und Psychotherapie, 2001, 29(4):285-295.

16. Azar R, Solomon R. Coping strategies of parents facing child illness. Journal of Pediatric Nursing, 2001,16(6):418-428.

17. Mott R, James R, Sperhac M. Nursing care of children and families, 2nd edition, New York, Harcourt Health Science, 1999p:612-623.

18. Jeprrett M. Parents of coming to know the care of chronically ill child. Journal of Advanced Nursing, 1994,19(6):1050-1056.

19. Fuller R, Schaller R. Health assessments - a nursing approach, 2nd ed. London, Lippincott, 1999:503-510.

20. Refatt H. Adaptation of mothers having children with Down syndrome [Masters thesis]. Cairo, Faculty of Nursing. Ain Shams University, 2002:102-114.

21. Doornbos MM. The problems and coping methods of caregivers of young adults with mental illness. Journal of Psychosocial Nursing, 1997, 35(9):22-26.

22. Melnyk B. Intervention study involving parents of hospitalized young children: an analysis of the past and future recommendations. Journal of Pediatric Nursing, 2000, 15(1):4-12.

23. Abd El-Megeed A. Stressors and coping patterns of mothers of mentally handicapped children [Masters thesis]. Alexandria, Faculty of Nursing, Alexandria University, 1999:1-15.

24. Singer GH. Meta-analysis of comparative studies of depression in mothers of children with and without developmental disabilities. American Journal of Mental Retardation, 2006, 111(3):155-169. 